\title{
Conversations with Lasker giants
}

$\mathbf{F}$ privilege of working with the Albert and Mary Lasker Foundation to write profiles on the prizewinners. Coverage of the 2014 laureates will be featured in the October issue. In addition to the news features on the prizes, I've had the pleasure of interviewing several of the previous years' laureates (Figure 1) for the series "Conversations with Giants in Medicine."

The interviews provide rich insights into scientific breakthroughs and inspiring glimpses of the researchers themselves. I can appreciate, however, that not everyone has the 30-45 minutes of free time necessary to watch an entire interview, so I've spliced together some of the laureates' finer moments into a highlight reel, narrated together with Claire Pomeroy, the President of the Albert and Mary Lasker Foundation.

Many of the laureates faced scientific and life challenges and triumphed over them with perseverance, resilience, support of colleagues and loved ones, and often a marvelous sense of humor. We can all be inspired by their stories. The video can be found at http://www.jci.org/ videos/cgm and will also be featured on the Lasker web site.

After watching the clips, I hope you are able to identify a bit more with these remarkable scientists. Many of them have humble beginnings and had no idea they'd end up as scientists and doctors. And many of them dream of what else they could have become - tennis players, teachers, and bartenders. Some had similar struggles, and all have experienced the joy of discovery. The true common thread among them is that they've all had extraordinary lives in science, as marked by being recipients of one of the most prestigious prizes in science, the Lasker Award.
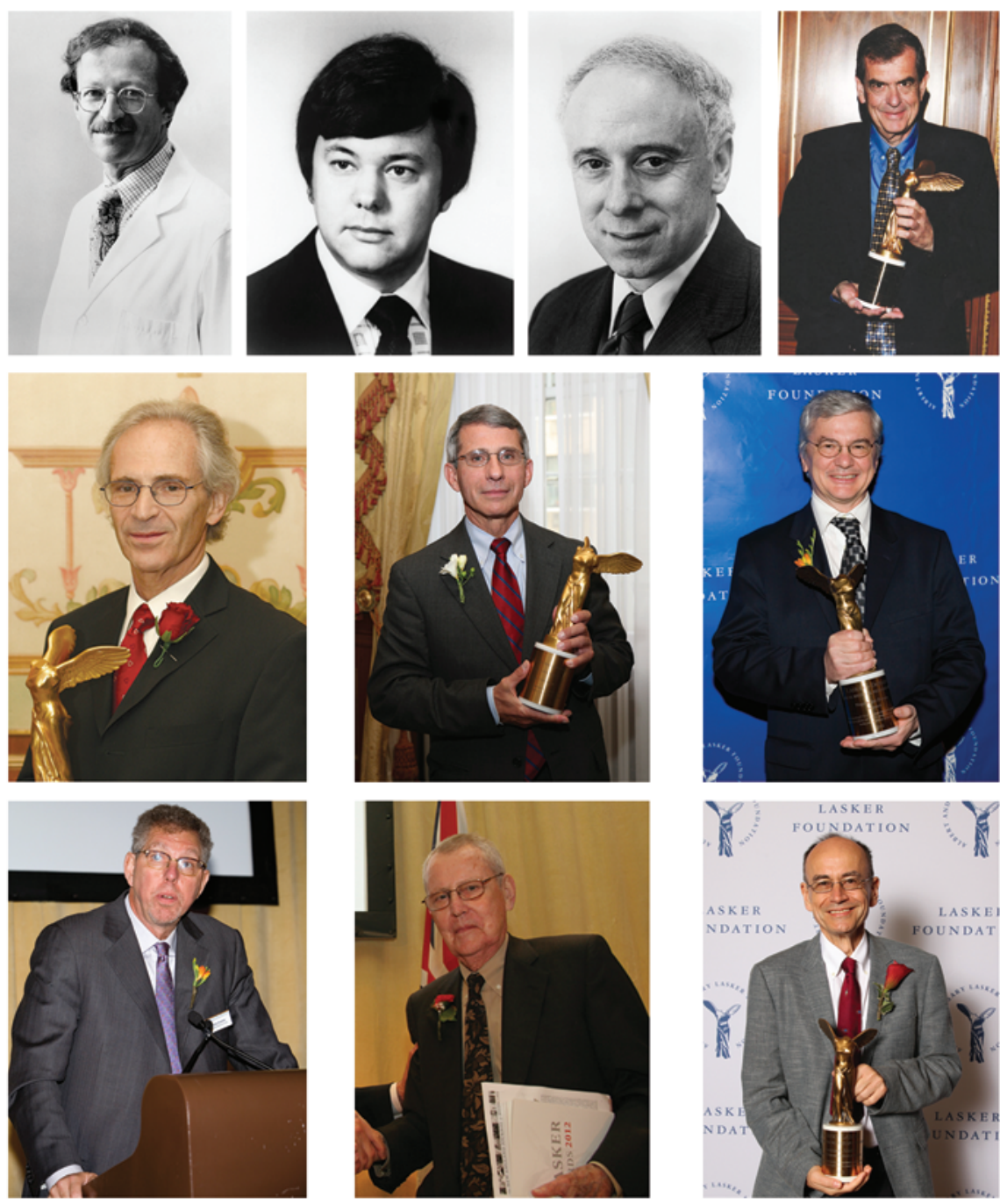

Figure 1. Lasker laureates interviewed in the series Conversations with Giants in Medicine. Harold Varmus, 1982 Albert Lasker Basic Medical Research Award. Michael Brown and Joseph Goldstein, 1985 Albert Lasker Basic Medical Research Award. Aaron Ciechanover, 2000 Albert Lasker Basic Medical Research Award. Marc Feldmann, 2003 Albert Lasker Clinical Medical Research Award. Anthony Fauci, 2007 Mary Woodard Lasker Award for Public Service. Napoleone Ferrara, 2010 Lasker DeBakey Clinical Medical Research Award. Jeffrey Friedman, 2010 Albert Lasker Basic Medical Research Award. Thomas Starzl, 2012 Lasker DeBakey Clinical Medical Research Award. Thomas C. Südhof, 2013 Albert Lasker Basic Medical Research Award. Photos reproduced with permission from the Albert and Mary Lasker Foundation.

Ushma S. Neill 